Supporting information for

\title{
Experimental and fractal characterization of the microstructure of shales from Sichuan Basin, China
}

\author{
Zhenhua Tian ${ }^{\dagger}$, Wei Wei ${ }^{*, \dagger}$, Shangwen Zhou ${ }^{\ddagger}$ David A. Wood ${ }^{\#}$, Jianchao Cai ${ }^{*, \dagger, \S}$ \\ $\dagger$ Institute of Geophysics and Geomatics, China University of Geosciences, Wuhan \\ 430074, China
}

PetroChina Research Institute of Petroleum Exploration \& Development, Beijing 100083, China

\#DWA Energy Limited, Lincoln, LN5 9JP, United Kingdom

${ }^{\S}$ State Key Laboratory of Petroleum Resources and Prospecting, China University of Petroleum, Beijing 102249, China

Corresponding authors:

*Wei Wei, Email: weiwei@cug.edu.cn.

*Jianchao Cai, Email: caijc@cug.edu.cn.

\section{Contents:}

Figure S1. SEM images for lacunarity analysis. 


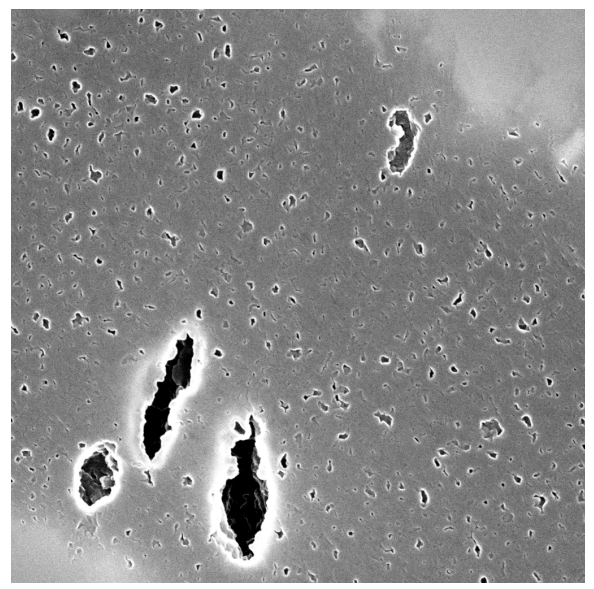

(a) P1-8 bit

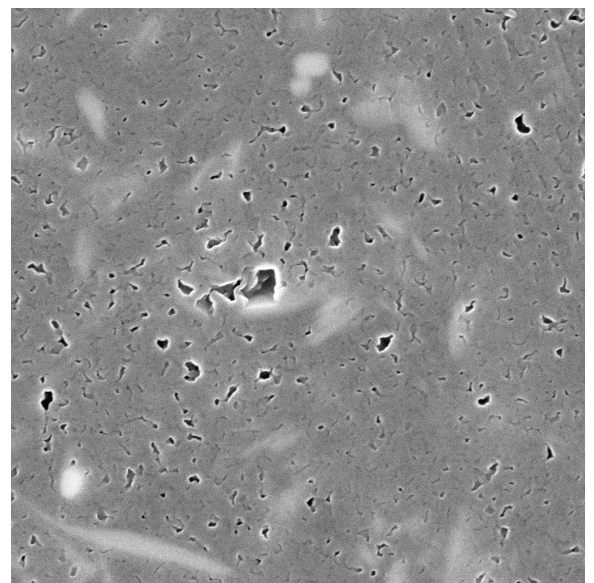

(c) P3-8bit

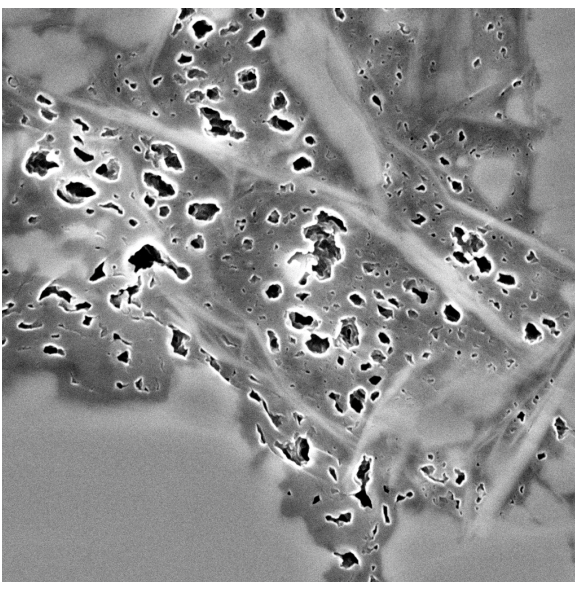

(b) P2-8bit

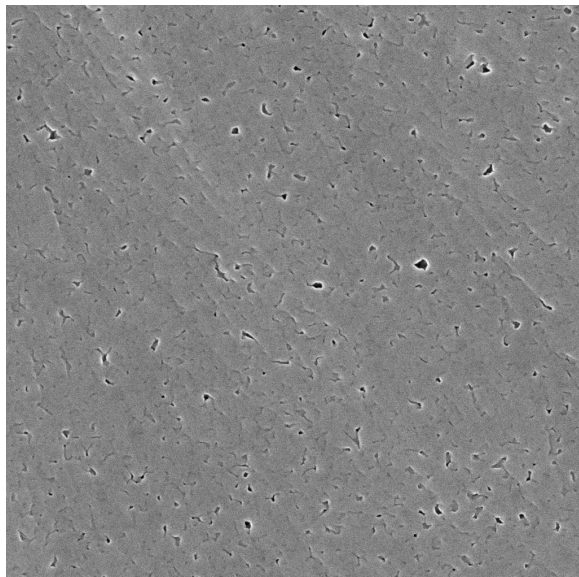

(d) P4-8bit

Figure S1. SEM images for lacunarity analysis. 